\title{
Green Synthesis of Silver Nanoparticles Using Cannabis sativa Extracts and Their Anti-Bacterial Activity
}

\author{
Sujata Mandal1 ${ }^{1}$, Sreekar B. Marpu${ }^{2}$, Roxana Hughes ${ }^{3}$, Mohammad A. Omary ${ }^{2 *}$, Sheldon Q. Shi ${ }^{*}$ \\ ${ }^{1}$ Department of Mechanical Engineering, University of North Texas, Denton, TX, USA \\ ${ }^{2}$ Department of Chemistry, University of North Texas, Denton, TX, USA \\ ${ }^{3}$ Department of Biological Sciences, University of North Texas, Denton, TX, USA \\ Email: ^sheldon.shi@unt.edu, ^omary@unt.edu
}

How to cite this paper: Mandal, S., Marpu, S.B., Hughes, R., Omary, M.A. and Shi, S.Q. (2021) Green Synthesis of Silver Nanoparticles Using Cannabis sativa Extracts and Their Anti-Bacterial Activity. Green and Sustainable Chemistry, 11, 38-48. https://doi.org/10.4236/gsc.2021.111004

Received: December 18, 2020

Accepted: February 23, 2021

Published: February 26, 2021

Copyright $\odot 2021$ by author(s) and Scientific Research Publishing Inc. This work is licensed under the Creative Commons Attribution International License (CC BY 4.0).

http://creativecommons.org/licenses/by/4.0/

\begin{abstract}
A procedure for the green synthesis of silver nanoparticles (AgNPs) using Cannabis sativa (hemp plant) as a stabilizing media was developed and antibacterial activity was tested. Within 30 minutes of heating the mixture of silver nitrate and hemp extract, the formation of silver nanoparticles took place under the complete absence of a chemical reducing or an additional stabilizing agent. The so-formed AgNPs were characterized using different optical spectroscopy and electron microscopy techniques. The initial formation of AgNPs was established from UV-Vis data based on surface plasmon resonance (SPR) of AgNPs at $\sim 417 \mathrm{~nm}$. The exact size, shape, and elemental composition of AgNPs were established from ESEM images and EDS data. The antibacterial activity of these nanoparticles was studied on Gram-positive Staphylococcus aureus, and Gram-negative Escherichia coli following Disk diffusion and Minimum Inhibitory Concentration (MIC) tests. Results showed that the biosynthesis of silver nanoparticles using hemp extract could be a simple, inexpensive, and biocompatible method.
\end{abstract}

\section{Keywords}

Hemp, Silver Nanoparticles, Green Synthesis, Pathogens

\section{Introduction}

Water contamination is one of the most persistent issues for public health. Waterborne pathogens have a devastating effect on human health. Multidrug-resistant bacteria, also known as superbugs, are being found in wastewater treatment plants 
[1]. A report by the United Nations, Interagency Coordination Group (2019) estimated that by 2030, the antimicrobial-resistant superbugs not only claimed the lives of 10 million people but would also destabilize the global economy [2]. As the demand for fresh drinking water is increasing, nanotechnology is gaining tremendous impetus in the present century to provide safe and affordable drinking water. The goal of the present research is to remove emerging pathogens from water without intensive use of harsh chemicals or the production of toxic byproducts. Nanomaterials can be synthesized by different techniques such as precipitation, chemical reduction, thermal decomposition, photochemistry, and microwave-assisted techniques [3] [4]. However, the major limitation for many of these techniques is the usage of strong reducing and stabilizing chemical reagents that pose a serious threat to the environment and human health [3]. In recent years, environmental and health concerns have stimulated researchers to devise novel and biological approaches to synthesizing nanomaterials using biological systems like microorganisms and plants, known as "green chemistry", approaches. In our previous efforts, we have shown the formation of size-tunable silver nanoparticles by photochemical reduction of $\mathrm{Ag}(\mathrm{I})$ salts in presence of biologically benign polymer media (no chemical reducing or nanoparticle growth-assisting reagents), as another manifestation of "green chemistry" [5].

The use of parts of the whole plant for nanoparticle synthesis offers exciting and potential advantages with a great capacity for investigation. Silver is one of the most widely used metals due to its inhibitory effect on bacteria and microorganisms by producing reactive oxygen species and thereby damaging the cell organelles [6] [7] [8]. Silver nanoparticles are considered a novel and probable substitute to standard antibiotic drugs as these pathogenic bacteria exhibit an increased multidrug resistance property.

Biosynthesis of silver nanoparticles using the abundant and sustainable plant resources is suitable for accomplishing the great demand for "biocompatible and green-synthesized nanoparticles", especially for the applications in biomedical and environmental areas. Hydroxyl and carboxyl groups found abundantly in the green plant materials act as a good source of reducing agents in the formation of metal nanoparticles, whereas the strong interaction between biomolecules and nanoparticles contributes to the excellent stability of the AgNPs [9] [10]. Moreover, the presence of phytonutrients in green resources plays an active role as a reducing and stabilizing agent for metal nanoparticles [11] [12].

Many researchers have reported the synthesis of silver nanoparticles using various natural products, e.g. green tea (Camellia sinensis) [13] [14], leaf broth of Acalypha indica, neem (Azadirachta indica) leaf extract [15] Aloe vera leaf extract [16] [17] [18], starch [19], and lemongrass leaves extract [20]. Hemp (Cannabis sativa) mainly contains cellulose, hemicellulose, and lignin, and has been widely cultivated in many tropical countries for its fiber content [21]. Hemp has been reported as a good source of food, oil, and fiber. It is also noted 
as a good source of pharmaceutical ingredient [22], as it contains various bioactive substances like cannabinoids, terpenes, ketones, fatty acids, and phenolic compounds demonstrated for their antibacterial, antifungal, anti-inflammatory, and anticancer properties [23] [24] [25]. Contrasting to the prior work in this field, in the present study, an eco-friendly method for the rapid synthesis of silver nanoparticles (AgNPs) using the hemp plant (Cannabis sativa) has been developed. No toxic chemicals were used as reducing agents or stabilizing agents during the synthetic protocol. The AgNPs were found to exhibit antibacterial efficacy against selective gram positive and gram-negative bacteria.

\section{Experimental}

\subsection{Materials and Methods}

Dry hemp hurd $(\mathrm{HH})$ was collected locally. Silver nitrate was purchased from Sigma-Aldrich (St. Louis, MO, USA), Luria Agar Base was obtained from (Santa Maria CA USA) and deionized water $\left(18.2 \mathrm{M} \Omega \mathrm{cm}^{-1}\right)$ was used during all experiments. The $\mathrm{HH}$ helps in reducing $\mathrm{Ag}(\mathrm{I})$ to $\mathrm{Ag}(0)$ and stabilizing the so formed $\mathrm{Ag}(0)$.

\subsection{Preparation of Hemp Hurdbased Carbon Extract (HHC)}

Two grams of $\mathrm{HH}$ were soaked in $100 \mathrm{~mL}$ of deionized water and boiled at $60^{\circ} \mathrm{C}$ for 1 hour. The solution was then filtered. The filtrate, henceforth termed as hemp hurd based carbon extract ( $\mathrm{HHC}$ ) and was stored at $4^{\circ} \mathrm{C}$ to carry out further experiments. Figure 1 showed the changes in physical color both for the concentrated and the dilute (after the addition of silver nitrate) HHC solutions.

\subsection{Biosynthesis of Silver Nanoparticles}

A $5 \mathrm{~mL}$ of aliquot (HHC) was added dropwise into $20 \mathrm{~mL}$ of $1 \mathrm{mM}$ and $5 \mathrm{mM}$ silver nitrate solutions respectively and mixed through constant magnetic stirring at temperature $70^{\circ} \mathrm{C}$ for 30 minutes. The effect of $\mathrm{AgNO}_{3}$ concentration and stirring time on the formation of AgNPs was analyzed. The formation of silver nanoparticles within the HHC media was confirmed from Figure 1. The colorless HHC solution exhibited a distinct brown color due to the formation of silver nanoparticles.
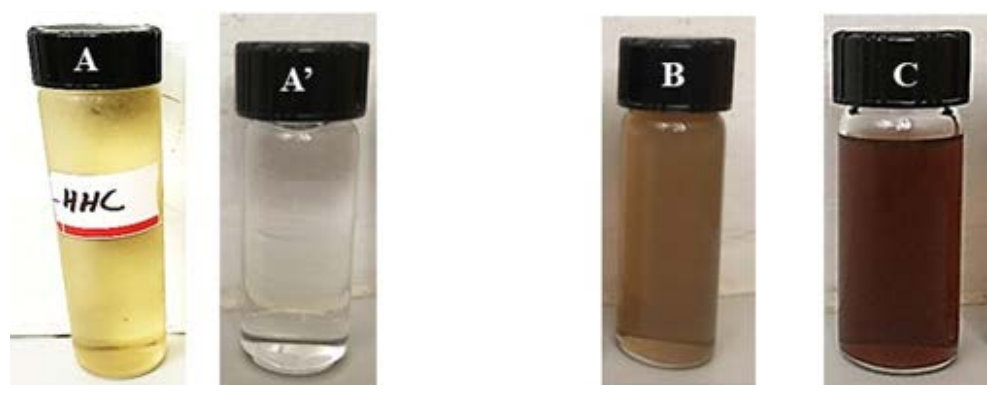

Figure 1. Daylight picture of HHC, HHC-silver salt, and HHC-AgNPs sample. AConcentrated $\mathrm{HH}-2 \%, \mathbf{A}^{\prime}-\mathrm{HHC}$ diluted with $\mathrm{AgNO}_{3}(1 \mathrm{mM}), \mathbf{B}$ and $\mathbf{C}-\mathrm{HHC}$ stabilized AgNPs sample at 15 minutes and 30 minutes of heating. 


\subsection{Characterization of the Synthesized Silver Nanoparticles (AgNPs)}

The successful formation of the silver nanoparticles was confirmed from the surface plasmon resonance (SPR) of AgNPs obtained using a UV-Vis spectrophotometer (Perkin-Elmer Lambda-900). The change in the physical color of the samples before and after the formation of AgNPs in HHC solution can be noticed in Figure 1. The SPR peaks were documented for two different concentrations ( $1 \mathrm{mM}$-HFN1 and $5 \mathrm{mM}$-HFN2) of silver nanoparticles at different stirring times of (15 minutes and 30 minutes respectively) The samples were labeled as HFN1-15, HFN1-30, HFN2-15, and HFN2-30, depending on the initial silver salt concentrations and stirring times. The morphology of the $\mathrm{HH}$ and size of AgNPs were examined using Environmental Scanning Electron Microscopy-ESEM-EDAX (ESEM FEI Quanta 200) and the elemental content of AgNPs was confirmed from Energy dispersive X-ray (EDX) spectroscopy, using an accelerating voltage of $15 \mathrm{kV}$ and an emission current of $12 \mu \mathrm{A}$. The basic information regarding functional groups presented in the $\mathrm{HH}$ that helped the bio reduction of silver ions and capping of AgNPs was determined using Fourier transform infra-red (FTIR) spectrophotometer (FT-IR Spectrometer Spectrum Two, PerkinElmer). The spectra of each sample were collected at a resolution of 4 $\mathrm{cm}^{-1}$ and 16 interferogram scans in the range of $400-4,000 \mathrm{~cm}^{-1}$. All observed absorption peaks were assigned to the best of our knowledge to confirm the various functional groups that were present in the hemp hurd $(\mathrm{HH})$ and AgNPs solutions.

\subsection{Antibacterial Activity of Silver Nanoparticles (AgNPs)}

Both Gram-negative (E. coli 25,922) and Gram-positive ( $S$. aureus 25,923) pathogenic waterborne bacteria were tested to investigate the antibacterial activity of so formed HHC stabilized AgNPs. An amount of $30.5 \mathrm{~g}$ of the Mueller-Hinton agar, dehydrated culture media was dissolved in $1 \mathrm{~L}$ of deionized water and then heated to dissolve completely. Disk diffusion tests were conducted to determine bacterial sensitivity towards AgNPs [26]. The Luria agar was sterilized in the autoclave at $120^{\circ} \mathrm{C}$ for 15 minutes. After cooling to around $45^{\circ} \mathrm{C}$, the broth was dispensed into sterile Petri dishes. A 3-way swab plate was prepared on an agar plate and filter disks ( $\sim 5 \mathrm{~mm}$ diameter) were placed at intervals on the surface of plates using sterile forceps. The plates were incubated at $37^{\circ} \mathrm{C}$ for 24 hours. $10 \mu \mathrm{l}$ aliquots of $1 \mathrm{mM}$ and $5 \mathrm{mM}$ AgNPs were impregnated on filter disk having uniform bacterial suspensions of $E$. coli and $S$. aureus. The diameter of the zone of inhibition (ZoI) was measured using photographic images of the agar plates [27].

Using the broth dilution method, the Minimum Inhibitory Concentration (MIC) of AgNPs was determined and the bactericidal effect of AgNPs was evaluated based on the Minimum Bactericidal Concentration (MBC). The MIC was defined as the lowest concentration of AgNPs, which inhibited bacterial growth. The MBC value was defined as the lowest concentration of nanoparticles that prevented the visible growth of bacteria on the agar plates after incubation. A 
volume of $0.2 \mathrm{~mL}$ of each bacterial strain was added to the test tube containing 1 $\mathrm{ml}$ broth (cell numbers reach $\sim 10^{8}-10^{9} \mathrm{CFU} / \mathrm{mL}$ after overnight grown culture) and was mixed with a serial dilution of $1 \mathrm{mM}$ (HFN1) AgNPs. Positive controls contained $1 \mathrm{~mL}$ of Luria broth and $0.2 \mathrm{~mL}$ of $E$. coli and $S$. aureus strain without containing AgNPs. The negative control contained only Luria broth. Tubes were incubated at $37^{\circ} \mathrm{C}$ for 24 hours. Each sample was examined for bacterial growth by monitoring the changes in the visual turbidity with the naked eye. The tubes that appeared to have no or little growth were plated on Luria broth agar plates to differentiate between bactericidal and/or bacteriostatic effect and these plates were incubated at $37^{\circ} \mathrm{C}$ for another 24 hours.

\section{Results and Discussion}

The formation of the AgNPs in the solution was always accompanied with a distinct color change arising from SPR of AgNPs in solution as noted in Figure 1. The concentrated HHC that exhibited a pale-yellow color (Sample A), turned colorless on dilution with silver salt solution (Sample $\mathbf{A}^{\prime}$ ). The colorless sample $\mathbf{A}^{\prime}$ on heating resulted in two different degrees of brown colors, depending on the heating time of the sample. At the fixed concentration of HHC and silver salt, the colorless solution initially turned into pale brown color on heating for 15 minutes and then on continuously heating for 30 minutes for the same solution turned into a dark-brown color. This color change was an indication of the successful formation of AgNPs, which occurred in the hemp hurd extract due to the reduction of $\mathrm{Ag}^{+}$ions to metallic $\mathrm{Ag}^{0}$ in the nanoscale, akin to our previous work [5]. The UV-Vis absorption spectra of the samples were recorded at 15 and 30 minutes of heating of $\mathrm{HHC}$ containing $1 \mathrm{mM}$ and $5 \mathrm{mM}$ silver nitrate precursor. The solution of HHC containing AgNPs exhibited UV-Vis absorption spectra with a peak maximum of around $450 \mathrm{~nm}$ originating from surface plasmon resonance (SPR) of AgNPs (Figure 2), well-documented in the literature [28]. Figure 2 showed the UV-Vis spectra of the AgNPs stabilized within hemp hurd extract at two different concentrations (HFN1-1 mM) and (HFN2-5 mM) of $\mathrm{AgNO}_{3}$ and at two different stirring times. The spectra were in good agreement with the reported literature [5] [28] indicating the formation of spherical AgNPs within the HHC solution. The broad UV-Vis spectra indicated the presence of different sized AgNPs in solution. As expected, the ESEM images in Figure 3(a) revealed the filamentous and porous structure of the fiber $(\mathrm{HH})$. There were some interfibrillar gaps that were detected on the surface of the untreated hemp hurd. The ESEM image (Figure 3(b)) showed the formation of relatively uniform size silver nanoparticles from hemp hurd extract. Figure 4 showed the particles were indeed spherical and exhibited a size range of $200-300 \mathrm{~nm}$. Both the images (Figure 3(b) and Figure 4) clearly showed some aggregation of particles within the hemp matrix; the aggregation could be due to the concentration effect in the solid form when the sample was dried. The SEM images showed that most of the AgNPs were spherical or quasi-spherical in shape as expected from UV-Vis 
data. In addition to simple ESEM images, the elemental characterization of so formed AgNPs within the HHC media was also performed using EDX spectroscopy. The major peaks appeared around $3 \mathrm{keV}$ confirming the chemical identity of nanoparticles stabilized within the HHC extract. These results demonstrated the first-ever formation of AgNPs within HHC media upon heating by facile "green synthesis" method. The size and shape tuning need to be investigated further.

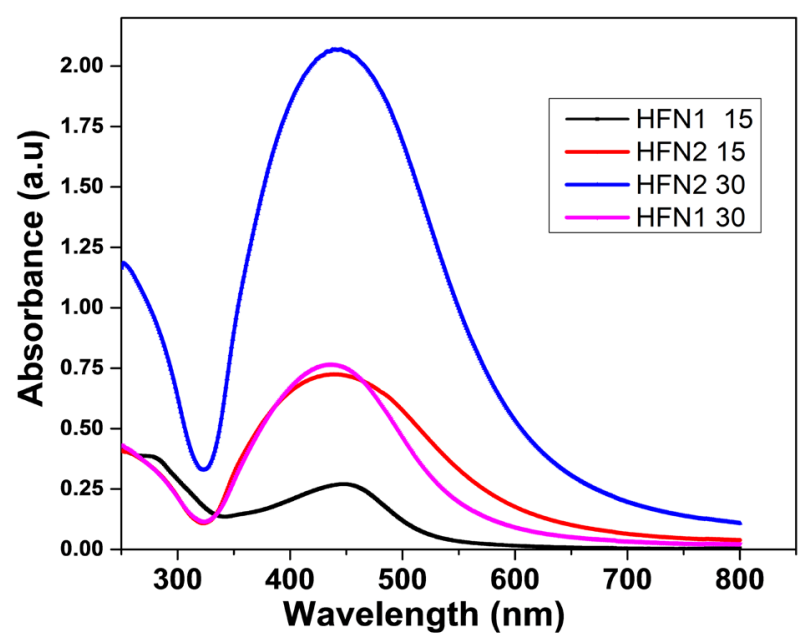

Figure 2. UV-Vis absorption spectra of AgNPs synthesized from HHC at (a) HFN1-1 $\mathrm{mM} \mathrm{AgNO}{ }_{3}$ concentrations, 15 minutes of heating (b) $\mathrm{HFN} 2-5 \mathrm{mM} \mathrm{AgNO}_{3}$ concentrations, 30 of minutes heating.
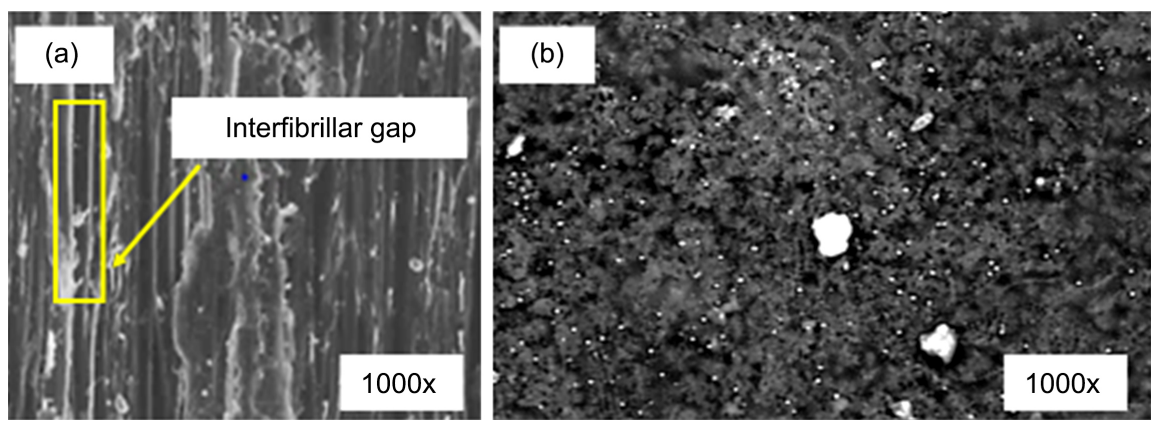

Figure 3. ESEM images of (a) dried HH and (b) HHC stabilized AgNPs.
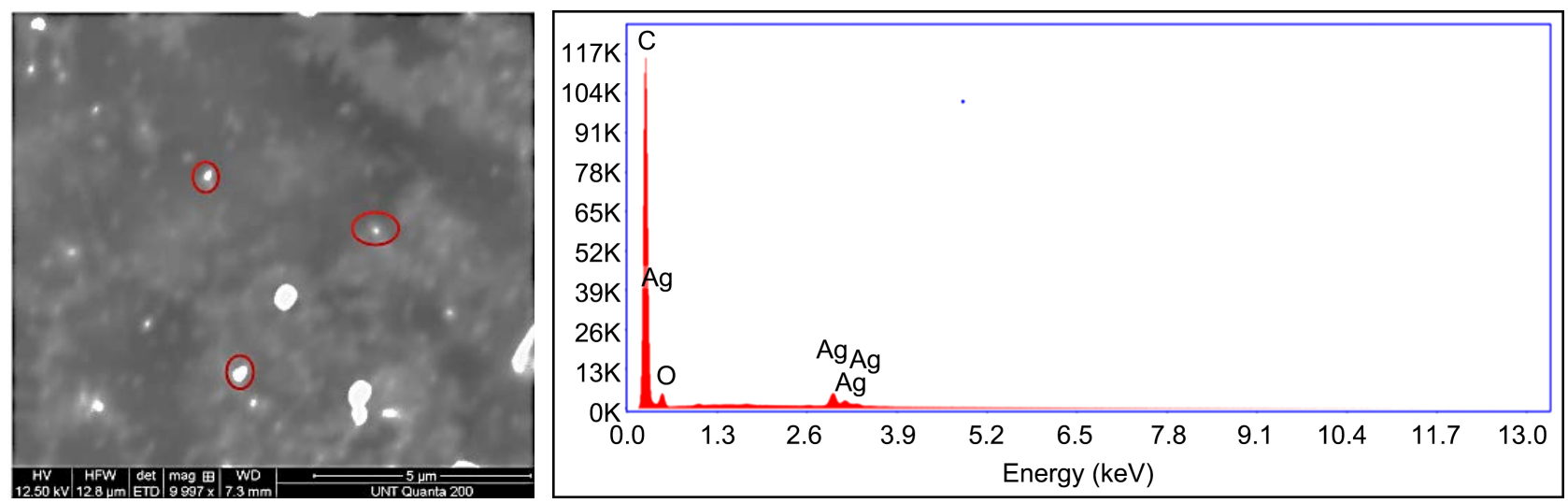

Figure 4. EDX image (left) and EDX spectra (right) of HHC stabilized AgNPs. 
The FTIR data obtained for the HHC and AgNPs stabilized within the HHC are shown in Figure 5. The spectra indicated the stretching and bending vibrations of diverse functional groups within the samples. Three strong peaks appeared at 599, 1,032, and 3,336 $\mathrm{cm}^{-1}$ for hemp hurd extract. These absorption peaks represented the $\mathrm{C}-\mathrm{H}$ vibration from cellulose, $\mathrm{C}-\mathrm{C}$ stretching vibration or $\mathrm{C}-\mathrm{OH}$ side group vibration, and -OH stretching respectively [29]. Four strong peaks were noticed in the spectra of hemp-stabilized silver nanoparticles sample at $792,1,310,1,628$, and $3,401 \mathrm{~cm}^{-1}$. Peaks at $3,401 \mathrm{~cm}^{-1}$ represent $\mathrm{OH}$-stretching, showing the presence of phenols. The stretching vibrations at $1,628 \mathrm{~cm}^{-1}$ are attributed to the $\mathrm{C}=\mathrm{O}$ stretch of the amide bonds. Characteristic absorption at $1,310 \mathrm{~cm}^{-1}$ represents the $\mathrm{C}-\mathrm{N}$ stretching due to the presence of aromatic amino group, while $792 \mathrm{~cm}^{-1}$ represented the bending vibration of the $\mathrm{C}-\mathrm{H}$ of the aromatic lignin group. These general assignments of IR bands were based on the literature [30] [31]. The HHC media being extracted from the plant source is expected to exhibit these chemical identities. These different chemical identities could play a crucial role in reducing the $\mathrm{Ag}(\mathrm{I})$ species to $\mathrm{Ag}(0)$ as well as for stabilizing the AgNPs [32].

The antibacterial activity of the AgNPs was investigated against both the Gram-positive and Gram-negative bacteria using the agar well diffusion assay. Figure 6 showed the zones of inhibition (ZoI) of the two strains of bacteria. The ZoI for Staphylococcus aureus and Escherichia coli bacteria for HHC, HFN1, and HFN2 samples were found to be around 15, 16, and $19 \mathrm{~mm}$, respectively. It was noticed from Figure 6 that the ZoI was significantly smaller for HHC vs HHC-stabilized AgNPs as expected though pharmacological properties of HHC were reported [32], no antibacterial activity was detected from the HHC control solution in the present work.

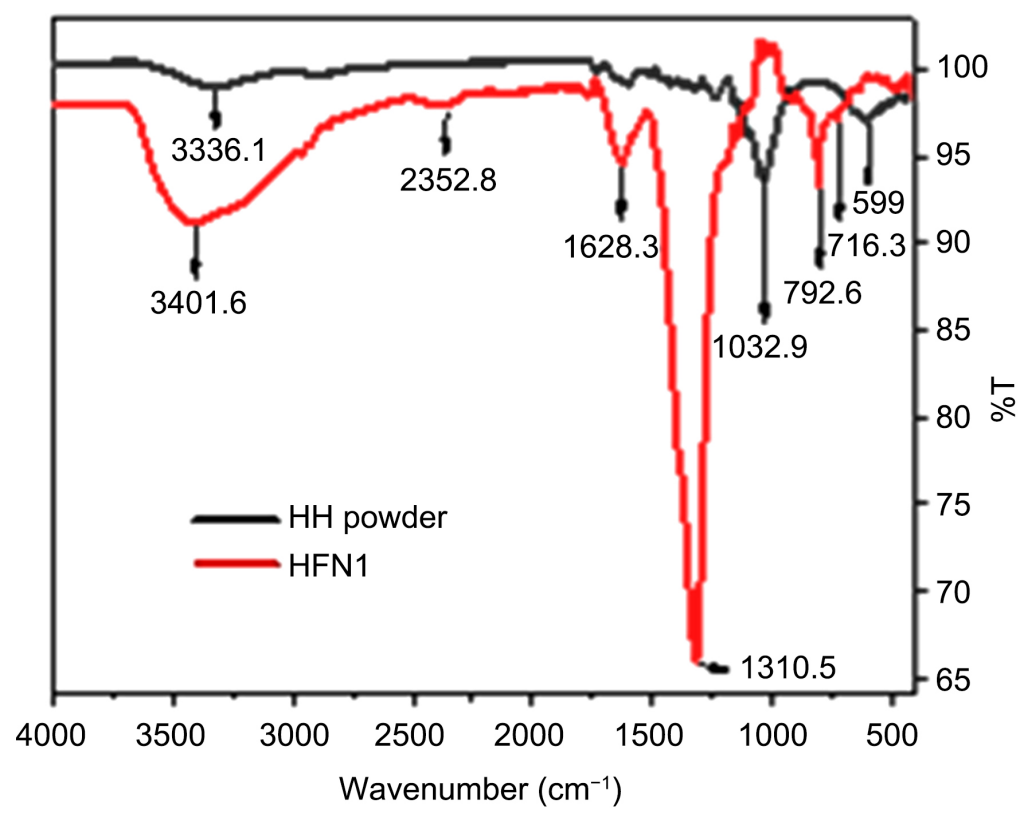

Figure 5. FT-IR spectra of dried HH and HHC synthesized AgNPs. 
Table 1. Antibacterial activities of silver nanoparticles prepared from various plant extract.

\begin{tabular}{cccccc}
\hline \multicolumn{2}{c}{ Zone of inhibition (mm) } & & & \\
\hline Plants related to HEMP species or similar plants & Mode of synthesis & Size of AgNPs & E. coli & S. aureus & References \\
\hline Kenaf (Hibiscus cannabinus) leaves & Prolonged heating & $\sim 100 \mathrm{~nm}$ & 11 & No activity & {$[33]$} \\
Jute fiber & Acid treatment & $500-600 \mathrm{~nm}$ & 18 & 15 & {$[34]$} \\
Hemp hurd (Cannabis sativa) & Heated at 70 ${ }^{\circ} \mathrm{C}$ for 30 mins & $100-200 \mathrm{~nm}$ & 18 & $16 \quad$ Our work \\
\hline
\end{tabular}

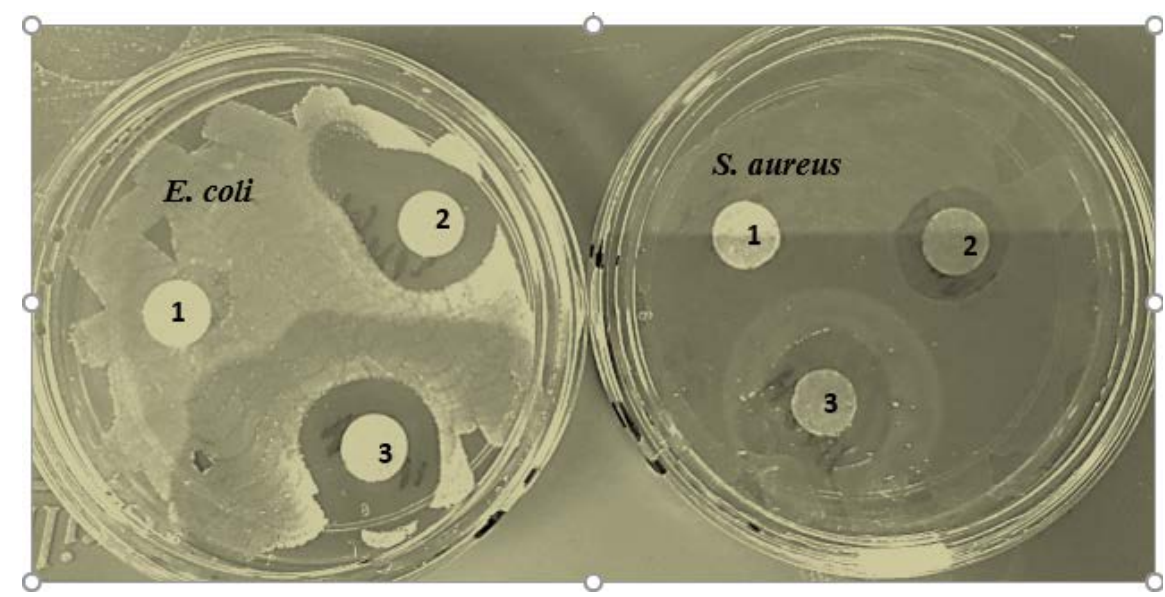

Figure 6. Antibacterial activity of (1) HHC, (2) HFN1, and (3) HFN2.

The bacteriostatic and bactericidal effects of synthesized nanoparticles have been screened by the determination of MIC and MBC against $E$. coli and S. aureus. In the primary screening, AgNPs showed a strong antibacterial activity with the MIC concentration of $12.77 \mu \mathrm{g} / \mathrm{mL}$ and the $\mathrm{MBC}$ concentration of 25 $\mu \mathrm{g} / \mathrm{mL}$ against both the pathogens respectively.

In order to understand the antipathogenic effects of HHC stabilized AgNPs, the results from our work were compared with various plant extract stabilized AgNPs from the literature. Table 1 showed the antibacterial activity of selective and most popular plant extract stabilized AgNPs in comparison with the present work.

\section{Conclusions}

A green synthesis method for silver nanoparticles using dry hemp hurd extract was developed and demonstrated. The synthesis route is simple, single-step, low energy-based, and benign, eliminating the usage of any hazardous chemicals to deem it "green". The formation of silver nanoparticles was confirmed from visual color change, UV-Vis, ESEM, and EDX data. The elemental analysis of AgNPs confirmed the presence of elemental silver with negligible traces of carbon and oxygen as expected. The synthesized AgNPs showed strong potential against both Gram-positive and Gram-negative bacteria. The antibacterial activity of the AgNPs against the Gram-positive S. aureus and Gram-negative E. coli was al- 
most identical. Nevertheless, this emerging innovation could become a substitute for chemically synthesized AgNPs and significantly improve the application of hemp hurd extract towards water filtration applications.

\section{Acknowledgements}

This work was supported by the University of North Texas, Toulouse Graduate School-Graduate Research Award to S.M. for her dissertation work under S.Q. Shi-whereas M.O.A acknowledges the Welch Foundation (B-1542) and the National Science Foundation (CHE-1413641) for supporting his group's contribution. We thank Dr. Calderon Jose (Department of Chemistry, University of North Texas) for the assistance with FT-IR data collection. ESEM and EDS were performed at the University of North Texas's Materials Research Facility (MRF), a shared research facility for multi-dimensional fabrication and characterization.

\section{Conflicts of Interest}

The authors declare there is no conflict of interest regarding the publication of this research manuscript.

\section{References}

[1] Luo, Y., Yang, F., Mathieu, J., Mao, D., Wang, Q. and Alvarez, P.J.J. (2014) Proliferation of Multidrug-Resistant New Delhi Metallo- $\beta$-Lactamase Genes in Municipal Wastewater Treatment Plants in Northern China. Environmental Science \& Technology Letters, 1, 26-30. https://doi.org/10.1021/ez400152e

[2] O’Neill, J. (2014) Antimicrobial Resistance: Tackling a Crisis for the Health and Wealth of Nations.

https://www.who.int/news/item/29-04-2019-new-report-calls-for-urgent-action-toavert-antimicrobial-resistance-crisis

[3] Kharissova, O.V., Dias, H.R., Kharisov, B.I., Pérez, B.O. and Pérez, V.M.J. (2013) The Greener Synthesis of Nanoparticles. Trends in Biotechnology, 31, 240-248. https://doi.org/10.1016/j.tibtech.2013.01.003

[4] Logeswari, P., Silambarasan, S. and Abraham, J. (2013) Ecofriendly Synthesis of Silver Nanoparticles from Commercially Available Plant Powders and Their Antibacterial Properties. Scientia Iranica, 20, 1049-1054.

[5] Marpu, S., Kolailat, S.S., Korir, D., Kamras, B.L., Chaturvedi, R., Joseph, A., Omary, M.A., et al. (2017) Photochemical Formation of Chitosan-Stabilized Near-Infrared-Absorbing Silver Nanoworms: A “Green" Synthetic Strategy and Activity on Gram-Negative Pathogenic Bacteria. Journal of Colloid and Interface Science, 507, 437-452. https://doi.org/10.1016/j.jcis.2017.08.009

[6] Bar, H., Bhui, D.K., Sahoo, G.P., Sarkar, P., De, S.P. and Misra, A. (2009) Green Synthesis of Silver Nanoparticles Using Latex of Jatropha curcas. Colloids and Surfaces A: Physicochemical and Engineering Aspects, 339, 134-139. https://doi.org/10.1016/j.colsurfa.2009.02.008

[7] Spadaro, J.A., Berger, T.J., Barranco, S.D., Chapin, S.E. and Becker, R.O. (1974) Antibacterial Effects of Silver Electrodes with Weak Direct Current. Antimicrobial Agents and Chemotherapy, 6, 637-642. https://doi.org/10.1128/AAC.6.5.637

[8] Feng, Q.L., Wu, J., Chen, G.Q., Cui, F.Z., Kim, T.N. and Kim, J.O. (2000) A Mecha- 
nistic Study of the Antibacterial Effect of Silver Ions on Escherichia coli and Staphylococcus aureus. Journal of Biomedical Materials Research, 52, 662-668. https://doi.org/10.1002/1097-4636(20001215)52:4<662::AID-JBM10>3.0.CO;2-3

[9] Xu, Q., Li, S., Wan, Y., Wang, S., Ma, B., She, Z., Dong, J., et al. (2017) Impacts of Silver Nanoparticles on Performance and Microbial Community and Enzymatic Activity of a Sequencing Batch Reactor. Journal of Environmental Management, 204, 667-673. https://doi.org/10.1016/j.jenvman.2017.09.050

[10] AshaRani, P.V., Low Kah Mun, G., Hande, M.P. and Valiyaveettil, S. (2009) Cytotoxicity and Genotoxicity of Silver Nanoparticles in Human Cells. ACS Nano, 3, 279-290. https://doi.org/10.1021/nn800596w

[11] Lok, C.N., Ho, C.M., Chen, R., He, Q.Y., Yu, W.Y., Sun, H., Tam, P.K., Chiu, J.F. and Che, C.M. (2006) Proteomic Analysis of the Mode of Antibacterial Action of Silver Nanoparticles. Journal of Proteome Research, 5, 916-924.

https://doi.org/10.1021/pr0504079

[12] Singh, P., Kim, Y.J., Zhang, D. and Yang, D.C. (2016) Biological Synthesis of Nanoparticles from Plants and Microorganisms. Trends in Biotechnology, 34, 588-599. https://doi.org/10.1016/j.tibtech.2016.02.006

[13] Gogoi, S.K., Gopinath, P., Paul, A., Ramesh, A., Ghosh, S.S. and Chattopadhyay, A. (2006) Green Fluorescent Protein-Expressing Escherichia coli as a Model System for Investigating the Antimicrobial Activities of Silver Nanoparticles. Langmuir, 22, 9322-9328. https://doi.org/10.1021/la060661v

[14] Vilchis-Nestor, A.R., Sanchez-Mendieta, V., Camacho-Lopez, M.A., GomezEspinosa, R.M., Camacho-Lopez, M.A. and Arenas-Alatorre, J.A. (2008) Solventless Synthesis and Optical Properties of $\mathrm{Au}$ and Ag Nanoparticles Using Camellia sinensis Extract. Materials Letters, 62, 3103-3105. https://doi.org/10.1016/j.matlet.2008.01.138

[15] Krishnaraj, C., Jagan, E.G., Rajasekar, S., Selvakumar, P., Kalaichelvan, P.T. and Mohan, N.J. (2010) Synthesis of Silver Nanoparticles Using Acalypha indica Leaf Extracts and Its Antibacterial Activity against Water Borne Pathogens. Colloids and Surfaces B: Biointerfaces, 76, 50-56. https://doi.org/10.1016/j.colsurfb.2009.10.008

[16] Shiv Shankar, S., Rai, A., Ahmad, A. and Sastry, M. (2004) Rapid Synthesis of Au, Ag, and Bimetallic Au Core-Ag Shell Nanoparticles Using Neem (Azadirachta indica) Leaf Broth. Journal of Colloid and Interface Science, 275, 496-502. https://doi.org/10.1016/j.jcis.2004.03.003

[17] Chandran, S.P., Chaudhary, M., Pasricha, R., Ahmad, A. and Sastry, M. (2006) Synthesis of Gold Nanotriangles and Silver Nanoparticles Using Aloe vera Plant Extract. Biotechnology Progress, 22, 577-583. https://doi.org/10.1021/bp0501423

[18] Vigneshwaran, N., Nachane, R.P., Balasubramanya, R.H. and Varadarajan, P.V. (2006) A Novel One Pot “Green” Synthesis of Stable Silver Nanoparticles Using Soluble Starch. Carbohydrate Research, 341, 2012-2018.

https://doi.org/10.1016/j.carres.2006.04.042

[19] Chandran, S.P., Chaudhary, M., Pasricha, R., Ahmad, A. and Sastry, M. (2006) Synthesis of Gold Nanotriangles and Silver Nanoparticles Using Aloevera Plant Extract. Biotechnology Progress, 22, 577-583. https://doi.org/10.1021/bp0501423

[20] Shankar, S.S., Rai, A., Ankamwar, B., Singh, A., Ahmad, A. and Sastry, M. (2004) Biological Synthesis of Triangular Gold Nanoprisms. Nature Materials, 3, 482-488. https://doi.org/10.1038/nmat1152

[21] Shankar, S.S., Rai, A., Ahmad, A. and Sastry, M. (2005) Controlling the Optical Properties of Lemongrass Extract Synthesized Gold Nanotriangles and Potential 
Application in Infrared-Absorbing Optical Coatings. Chemistry of Materials, 17, 566-572. https://doi.org/10.1021/cm048292g

[22] Mandal, S. and Shi, S.Q. (2020) Agricultural Plants and Their Antimicrobial Activities-A Mini Review.

[23] Chopra, R.N. and Chopra, R.N. (1969) Supplement to Glossary of Indian Medicinal Plants.

[24] Khan, B.A., Warner, P. and Wang, H. (2014) Antibacterial Properties of Hemp and Other Natural Fibre Plants: A Review. BioResources, 9, 3642-3659.

https://doi.org/10.15376/biores.9.2.3642-3659

[25] Singh, P., Pandit, S., Garnæs, J., Tunjic, S., Mokkapati, V.R., Sultan, A., Baun, A., et al. (2018) Green Synthesis of Gold and Silver Nanoparticles from Cannabis sativa (Industrial Hemp) and Their Capacity for Biofilm Inhibition. International Journal of Nanomedicine, 13, 3571. https://doi.org/10.2147/IJN.S157958

[26] Pearce, D.D., Mitsouras, K. and Irizarry, K.J. (2014) Discriminating the Effects of Cannabis sativa and Cannabis indica: A Web Survey of Medical Cannabis Users. Journal of Alternative and Complementary Medicine, 20, 787-791. https://doi.org/10.1089/acm.2013.0190

[27] Tenover, F.C., Arbeit, R.D., Goering, R.V., Mickelsen, P.A., Murray, B.E., Persing, D.H. and Swaminathan, B. (1995) Interpreting Chromosomal DNA Restriction Patterns Produced by Pulsed-Field Gel Electrophoresis: Criteria for Bacterial Strain Typing. Journal of Clinical Microbiology, 33, 2233-2239. https://doi.org/10.1128/jcm.33.9.2233-2239.1995

[28] Singh, P., Singh, H., Kim, Y.J., Mathiyalagan, R., Wang, C. and Yang, D.C. (2016) Extracellular Synthesis of Silver and Gold Nanoparticles by Sporosarcina koreensis DC4 and Their Biological Applications. Enzyme and Microbial Technology, 86, 75-83. https://doi.org/10.1016/j.enzmictec.2016.02.005

[29] Ashraf, J.M., Ansari, M.A., Khan, H.M., Alzohairy, M.A. and Choi, I. (2016) Green Synthesis of Silver Nanoparticles and Characterization of Their Inhibitory Effects on AGEs Formation Using Biophysical Techniques. Scientific Reports, 6, Article No. 20414. https://doi.org/10.1038/srep20414

[30] Huang, J., Li, Q., Sun, D., Lu, Y., Su, Y., Yang, X., Wang, H., Wang, Y., Shao, W., He, N., Hong, J. and Chen, C. (2007) Biosynthesis of Silver and Gold Nanoparticles by Novel Sundried Cinnamomum camphora Leaf. Nanotechnology, 18, Article ID: 105104. https://doi.org/10.1088/0957-4484/18/10/105104

[31] Akter, M., Rahman, M.M., Ullah, A.A., Sikder, M.T., Hosokawa, T., Saito, T. and Kurasaki, M. (2018) Brassica rapa var. japonica Leaf Extract Mediated Green Synthesis of Crystalline Silver Nanoparticles and Evaluation of Their Stability, Cytotoxicity, and Antibacterial Activity. Journal of Inorganic and Organometallic Polymers and Materials, 28, 1483-1493. https://doi.org/10.1007/s10904-018-0818-7

[32] Khan, B.A., Wang, J., Warner, P. and Wang, H. (2015) Antibacterial Properties of Hemp Hurd Powder against E. coli. Journal of Applied Polymer Science, 132, 41588. https://doi.org/10.1002/app.41588

[33] Bindhu, M.R. and Umadevi, M. (2013) Synthesis of Monodispersed Silver Nanoparticles Using Hibiscus cannabinus Leaf Extract and Its Antimicrobial Activity. Spectrochimica Acta Part A: Molecular and Biomolecular Spectroscopy, 101, 184-190. https://doi.org/10.1016/j.saa.2012.09.031

[34] Rabbi, M.A., Rahman, M.M., Minami, H., Habib, M.R. and Ahmad, H. (2020) Ag Impregnated Sub-Micrometer Crystalline Jute Cellulose Particles: Catalytic and Antibacterial Properties. Carbohydrate Polymers, 233, Article ID: 115842.

https://doi.org/10.1016/j.carbpol.2020.115842 